\title{
Effects of changes in nutrient loading and composition on hypoxia dynamics and internal nutrient cycling of a stratified coastal lagoon
}

\author{
Yafei Zhu ${ }^{1,2}$, Andrew McCowan ${ }^{2}$, and Perran L. M. $\operatorname{Cook}^{1}$ \\ ${ }^{1}$ Water Studies Centre, Monash University, Clayton 3800, Australia \\ ${ }^{2}$ Water Technology Pty Ltd, 15 Business Park Drive, Notting Hill 3168, Australia \\ Correspondence to: Yafei Zhu (yafei.zhu@monash.edu)
}

Received: 10 April 2017 - Discussion started: 11 April 2017

Revised: 30 August 2017 - Accepted: 5 September 2017 - Published: 6 October 2017

\begin{abstract}
The effects of changes in catchment nutrient loading and composition on the phytoplankton dynamics, development of hypoxia and internal nutrient dynamics in a stratified coastal lagoon system (the Gippsland Lakes) were investigated using a 3-D coupled hydrodynamic biogeochemical water quality model. The study showed that primary production was equally sensitive to changed dissolved inorganic and particulate organic nitrogen loads, highlighting the need for a better understanding of particulate organic matter bioavailability. Stratification and sediment carbon enrichment were the main drivers for the hypoxia and subsequent sediment phosphorus release in Lake King. High primary production stimulated by large nitrogen loading brought on by a winter flood contributed almost all the sediment carbon deposition (as opposed to catchment loads), which was ultimately responsible for summer bottom-water hypoxia. Interestingly, internal recycling of phosphorus was more sensitive to changed nitrogen loads than total phosphorus loads, highlighting the potential importance of nitrogen loads exerting a control over systems that become phosphorus limited (such as during summer nitrogen-fixing blooms of cyanobacteria). Therefore, the current study highlighted the need to reduce both total nitrogen and total phosphorus for water quality improvement in estuarine systems.
\end{abstract}

\section{Introduction}

Excessive anthropogenic nutrient loading, particularly nitrogen, has led to widespread hypoxia and other ecological damages in estuarine and coastal areas (Howarth et al., 2011). About half of the known hypoxic events have been caused by eutrophication (Diaz and Rosenberg, 2008). High primary production as a result of eutrophication can lead to hypoxia or anoxia in poorly mixed bottom water and subsequently enhance the recycling of both nitrogen and phosphorus, which again can reinforce eutrophication (Correll, 1998). This has been found in many stratified estuarine systems around the world, including the Baltic Sea (Vahtera et al., 2007) and the Black Sea (Capet et al., 2016), the Neuse River Estuary (Paerl et al., 1995), and the Gippsland Lakes (Scicluna et al., 2015). The magnitude of sediment phosphorus release is related to severity of bottom-water dissolved oxygen (DO) depletion as well as the duration of hypoxia and/or anoxia. For example, Conley et al. (2002) found that the annual change in dissolved inorganic phosphorus (DIP) in the Baltic Sea was proportional to the area covered by hypoxic water rather than the catchment phosphorus load.

Although some researchers argued that a reduction in both nitrogen and phosphorus were important to improve hypoxia in areas such as the Gulf of Mexico (Rabalais et al., 2007) and the Baltic Sea (Vahtera et al., 2007), others considered that nitrogen should be the primary factor driving marine coastal eutrophication (Diaz, 2001; Hagy et al., 2004; Howarth and Marino, 2006) and thus hypoxia. Regardless of this controversy, the global river export of phosphorus to the coastal ocean has already decreased significantly as a result of advances in wastewater treatment technology since the start of the 21st century; however, nitrogen export still remained high (Howarth et al., 2011). The form and composition of nitrogen export, i.e. dissolved inorganic nitrogen (DIN) and particulate organic nitrogen (PON), can also have a significant impact on receiving coastal waters, as they have different residence times and bioavailability. Seitzinger 
et al. (2002) showed that total global PON and DIN export by rivers in 1990 were similar, but the DIN : PON ratios varied from region to region. Generally speaking, the DIN : PON ratio was much higher in areas with larger population, indicating that anthropogenic activities had a larger influence on DIN export compared to PON export. The global DIN input to coastal systems was predicted to increase by more than $120 \%$ to 47 million $\mathrm{t}$ year $^{-1}$ by 2050 compared to the level in 1990 (Seitzinger et al., 2002). The relative importance of internally generated (primary production stimulated by nitrogen export) and externally supplied organic matter in hypoxia has only been previously studied by a few researchers (Paerl et al., 1998; Turner et al., 2007). Paerl et al. (1998) showed that hypoxia in estuaries can be stimulated either by internally generated or externally supplied organic matter depending on the meteorological and hydrological conditions. Most importantly, there was a lack of understanding of how different forms of nitrogen (i.e. DIN and PON) in the catchment load can influence the dynamics of hypoxia and the sediment phosphorus cycle in estuarine systems.

Coupled hydrodynamic and biogeochemical models are now increasingly sophisticated and can capture complex biogeochemical feedbacks. There have been a number of successful applications of these models in studying the effects of changes in anthropogenic nutrient loading on the water quality dynamics in estuarine waters (Kiirikki et al., 2001; Webster et al., 2001; Neumann et al., 2002; Pitkänen et al., 2007; Skerratt et al., 2013). However, all these studies primarily focused on the effectiveness of alternative management scenarios for estuarine systems. None of these studies have addressed the sensitivity of hypoxia dynamics and internal nutrient cycling to different forms of nitrogen, phosphorus and organic carbon inputs, which has important scientific and management implications for estuarine water quality.

In this study, we utilised a 3-D coupled hydrodynamicbiogeochemical model to evaluate (1) the sensitivity of phytoplankton and hypoxia dynamics in the Gippsland Lakes to the change in composition of anthropogenic nutrient loading and (2) the consequent impact on internal nutrient dynamics.

\section{Method}

\subsection{Study site}

The Gippsland Lakes, located in the southeast of Australia, are the largest estuarine coastal lagoon system in Australia (Fig. 1). The system consists of three main lakes with a total surface area of about $360 \mathrm{~km}^{2}$. The depths vary from less than $4 \mathrm{~m}$ deep in Lake Wellington to 5-10 $\mathrm{m}$ deep in Lake King. Lake Wellington and Lake Victoria are linked by the McLennan Strait, which is a narrow channel about $10 \mathrm{~km}$ long, $80 \mathrm{~m}$ wide and up to $11 \mathrm{~m}$ deep. The lakes are connected to the ocean through an artificial entrance at Lakes Entrance constructed in 1889. The Gippsland Lakes has a

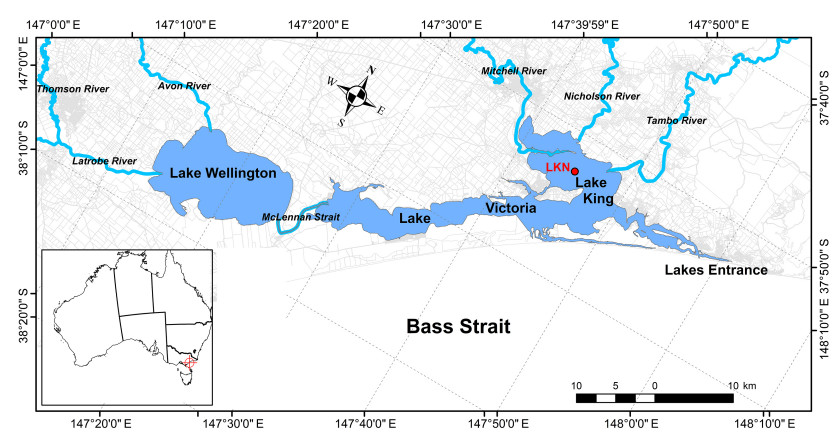

Figure 1. Gippsland Lakes, major tributaries and the location of Lake King North (LKN).

catchment area of more than $20000 \mathrm{~km}^{2}$ and mainly receives freshwater inflow from six major rivers as shown in Fig. 1.

The Gippsland Lakes suffer recurring blooms of toxic nitrogen-fixing cyanobacteria in summers following floods in winter and spring. Together with stratification, high carbon delivery to the sediment in winter and spring following floodinduced diatom and dinoflagellate blooms caused depleted bottom-water oxygen in summer and a subsequent large release of phosphorus from the sediment in the central basins of Lake King and Victoria. Between July and August 2011, the Gippsland Lakes experienced two consecutive floods. In the following summer, a large toxic cyanobacteria bloom occurred in the lakes that persisted from mid-November 2011 to the end of January 2012. It was found that sediment phosphorus release as a result of depleted bottom DO rather than catchment load supplied most of the phosphorus to support the development of the bloom (Zhu et al., 2016).

\subsection{Model description}

The coupled model used in the current study was developed by Zhu et al. (2016) using DHI's MIKE3 FM and ECO Lab. The model consists of two components, the hydrodynamic model and the biogeochemical model. The hydrodynamic model simulated the transport and turbulent mixing in the water column. The horizontal domain of the hydrodynamic model was discretised as triangular and quadrilateral elements with element areas ranging from $1500 \mathrm{~m}^{2}$ near the entrance channel and $3 \mathrm{~km}^{2}$ in Bass Strait. The model had a total of 33 fixed $z$ and varying sigma layers for the vertical discretisation, with height from less than $0.5 \mathrm{~m}$ close to the surface to $5 \mathrm{~m}$ down to the bottom. Smagorinsky formulations for the horizontal and the standard $\kappa-\epsilon$ model for the vertical have been used to simulate the transport and turbulent mixing in the water column. A scaled eddy formulation was used for the horizontal and vertical dispersion processes, which made the dispersion coefficients directly related to the eddy viscosity calculated by the turbulence models. With the same wind forcing data and model domain, a spectral wave model was also developed for the Gippsland Lakes, using 
DHI's MIKE 21 spectral wave module. The wave model results were used to calculate wind-wave shear stress. Since there were not any measured wave data inside the lakes, the default wave input parameters have been used.

The water quality model contains 41 state variables describing the chemical, biological and ecological processes occurring in the water column and sediment compartments. The model included three groups of phytoplankton, which were $\mathrm{N}$-fixing cyanobacteria, vertically migrating dinoflagellates and fast-growing diatoms. One group of grazers was included and configured to avoid grazing on cyanobacteria. The mortality of phytoplankton together with the catchment input was the major source of organic matter. The organic matter was represented by particulate organic carbon (POC), $\mathrm{PON}$, and particulate organic phosphorus (POP) and was further divided into labile and refractory fractions. To simplify, the dissolved organic carbon and nutrients and the hydrolysis process (conversion from particulate to dissolved organic carbon and nutrients) have not been modelled explicitly. Instead, the model has been configured in the way that mineralisation of particulate organic carbon and nutrients took place without going through hydrolysis first. An accumulation of organic matter layer in the bottom water was formed due to settling. Some of the accumulated organic matter would deposit in the sediment and some would return to the water column by resuspension. The rates of deposition and resuspension were calculated based on the modelled local shear stress and the critical shear stress defined for deposition and resuspension. Burial was active when the total thickness of sediment organic matter exceeded $20 \mathrm{~cm}$. The thickness was calculated using a density of $16.959 \mathrm{~kg} \mathrm{C} \mathrm{m}^{-3}$ assuming a porosity of 0.8 . The buried sediment organic matter was removed from simulations.

It has previously been shown that internal phosphorus recycling is a key process within the Gippsland Lakes, requiring a refined implementation into water quality models (Webster et al., 2001). The present model overcame previous limitations by implementing sorption and desorption of sediment phosphate and bioirrigation into the model, enabling an accurate simulation of sediment phosphorus dynamics. The sorption and desorption of sediment phosphate were modelled explicitly based on the penetration depth of oxygen and nitrate and the sediment iron concentration, which was a spatially varying constant estimated by using the data collected from previous studies. The impact of bioirrigation was modelled by introducing a scaling factor that was used to adjust the diffusion rates of oxygen and inorganic nutrients at the sediment-water interface. The scaling factor was a function of temperature, DO and labile organic matter. In addition, the model also included a simple cohesive sediment transport module with two bed layers that took into account the salinity and shear stress due to wind-wave and current interactions.

The initial conditions, especially the sediment nutrient storage, could have a large impact on the model simulation.
The initial condition of organic carbon, nitrogen, and phosphorus and inorganic nitrogen in the sediment was estimated by iteratively simulating the model for a year, and the concentration at the end of a simulation was used as the initial condition for successive simulations. This was repeated until the sediment nutrient inventory did not change substantially by the end of the simulation. A spatially varying sediment iron-bound phosphate distribution was estimated based on previous field studies.

The total sediment DIN, iron-bound phosphate, and labile POC, PON, and POP in the Gippsland Lakes were approximately $118 \mathrm{t} \mathrm{N}, 3234 \mathrm{t} \mathrm{P}, 2861 \mathrm{t} \mathrm{C}, 238 \mathrm{t} \mathrm{N}$, and $34 \mathrm{t} \mathrm{P}$, respectively. The coupled model was calibrated and validated for the period between May 2010 and July 2012 and it has reproduced the hydrodynamic and biogeochemical conditions in the lakes well and successfully replicated the 2011-2012 summer cyanobacterial bloom (Zhu et al., 2016).

\subsection{Nutrient scenarios}

Catchment nutrient load data were obtained from the Water Measurement Information System (previously was known as Victorian Water Resources Data Warehouse), which is managed by the Department of Environment, Land, Water and Planning (DELWP). The nutrient data consisted of various constituent concentrations including total nitrogen (TN), nitrate, nitrite, ammonia, total Kjeldahl nitrogen (TKN), total phosphorus (TP) and DIP. The concentrations of the total inorganic and particulate organic nutrients were first calculated using the raw data, and the particulate organic nutrients were then further divided into labile and refractory fractions. There were no measured data for the riverine carbon input; thus, the catchment organic carbon load was estimated using the organic nitrogen load, assuming a $\mathrm{C}: \mathrm{N}$ weight ratio of 10 (Meybeck, 1982), which also agrees with previous studies that showed that the sediment $\mathrm{C}: \mathrm{N}$ weight ratio was around 8 to 13 in the Gippsland Lakes (Longmore, 2000; Holland et al., 2013). It can be assumed that organic matter with a $\mathrm{C}: \mathrm{N}$ ratio close to the Redfield ratio, 5.7 (on a mass basis), should be labile. The Redfield C:N ratio was close to $60 \%$ of that of the estimated catchment $\mathrm{C}: \mathrm{N}$ ratio. Therefore, it was assumed that $60 \%$ of the catchment organic nutrient loads were labile and the rest were refractory and not bioavailable over the timescale of water residence time. Therefore, a very low mineralisation rate $\left(0.005 \mathrm{day}^{-1}\right)$ was used for the refractory portion (Zhu et al., 2016).

On average, the western rivers (Latrobe, Thomson and Avon rivers) and eastern rivers (Mitchell, Tambo and Nicholson rivers) each supplied approximately 52 and $48 \%$ of the riverine freshwater inflows to the lake system. However, the western rivers contributed up to approximately $70 \%$ of catchment nutrient loads between May 2010 and July 2012 (Table 1). The majority of these nutrients were delivered during the wet season and were associated with major floods (Fig. 2). The DIN : PON ratio for the eastern rivers was only 


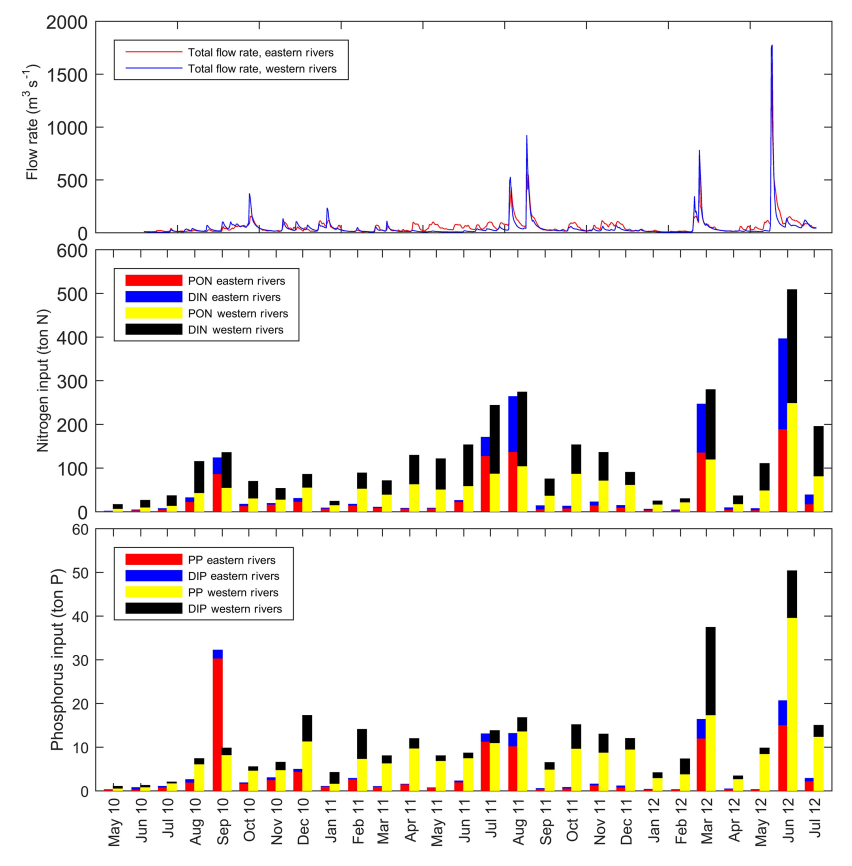

Figure 2. River flow rates and monthly catchment nutrient input.

Table 1. Nutrient loads between May 2010 and July 2012.

\begin{tabular}{lrr}
\hline & Eastern rivers & Western rivers \\
\hline $\mathrm{DIN}(\mathrm{tN})$ & 411.92 & 1403.76 \\
$\mathrm{PON}^{\mathrm{a}}(\mathrm{tN})$ & 681.58 & 1197.09 \\
$\mathrm{DIP}(\mathrm{tP})$ & 18.45 & 77.77 \\
$\mathrm{PP}^{\mathrm{a}, \mathrm{b}}(\mathrm{tP})$ & 89.82 & 171.18 \\
$\mathrm{POC}(\mathrm{tC})$ & 6815.82 & 11970.9 \\
\hline
\end{tabular}

a The refractory faction has been excluded.

${ }^{\mathrm{b}} \mathrm{PP}$ is particulate $\mathrm{P}$, which is $\mathrm{TP}-\mathrm{DIP}$.

0.6 compared to 1.17 for the western rivers, consistent with more intense human activities in the western catchment. In other words, the percentages of riverine bioavailable nitrogen (DIN + labile PON) delivered to the Gippsland Lakes in the form of labile PON were around 63 and $46 \%$ for the eastern and western rivers, respectively. These numbers were very close to the ones reported for the other major rivers around the world, including the Mississippi (40\%), Amazon (62\%), and Yangtze (45\%) rivers (Mayer et al., 1998). This confirmed that $60 \%$ of the particulate nutrients being labile was a reasonable assumption to describe the characteristics of catchment organic nutrient loads. The TN: TP ratios for both eastern and western rivers were around 10 (on a mass basis), which was close to the Redfield ratio of 7.23 (on a mass basis). While the DIN : DIP ratios were 22.3 and 18 (on a mass basis) for the eastern rivers and western rivers, respectively.

For the current study, we used the calibrated model as the base case and simulated a number of nutrient load scenar-

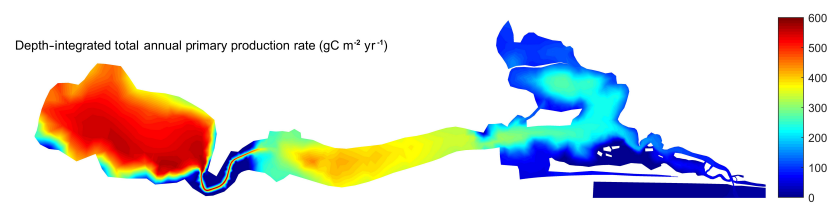

Figure 3. Modelled depth-integrated total annual primary production for the base case.

ios for the same period. There were five sets of scenarios with adjusted loads for DIN, PON, TN (DIN+PON), TP (DIP + particulate $\mathrm{P})$, or TN and TP. In all the scenarios, $\mathrm{POC}$ values were set to vary at the same proportion as PON. Since POC load was estimated based on PON load, the C: N ratio in the model was also used to define if particulate matter was labile or refractory. Each set of scenarios had eight simulations that decreased and increased the load by 25,50 , 75 and $100 \%$. To ensure the consistency of the comparisons and analysis, all scenarios had the same initial conditions including the sediment nutrient inventory, which was derived from the base case. The response of bottom-water DO and sediment processes to different nutrient scenarios over the 2year simulation period between May 2010 and July 2012 was analysed and discussed, with the focus on the central basins of northern Lake King where the most severe hypoxia, highest sediment DIP fluxes and cyanobacterial blooms were located.

\section{Results}

\subsection{Primary production}

The annual total primary production (TPP) rate in Lake Wellington could reach as high as $600 \mathrm{~g} \mathrm{C} \mathrm{m}^{2}$ year $^{-1}$, about $350 \mathrm{~g} \mathrm{C} \mathrm{m}^{2}$ year $^{-1}$ in Lake Victoria followed by $250 \mathrm{~g} \mathrm{C} \mathrm{m}^{2}$ year $^{-1}$ in Lake King (Fig. 3). The spatial variation in primary production rate was caused by a number of factors, mainly the higher nutrient loads from the western rivers and longer residence time for Lake Wellington. As a result, Lake King only contributed about $12 \%$ of the TPP in the lakes. The total catchment POC load was only $7.5 \%$ of the TPP for the simulation period and was expected to have a minor impact on the sediment biogeochemistry in the lakes. As expected, the TPP in Lake King and the catchment nutrient load had a positive correlation (Fig. 4). TPP was most sensitive to changes in TN + TP loads and least sensitive to reductions in PON loads and increases in TP loads. TPP was very sensitive to reductions in TP loads at reductions $>25 \%$. The $\mathrm{TN}$ reduction scenarios displayed an intermediate response. TPP was more sensitive to reductions in TN than TP until reduction exceeded $75 \%$ when TPP became more sensitive to TP. 


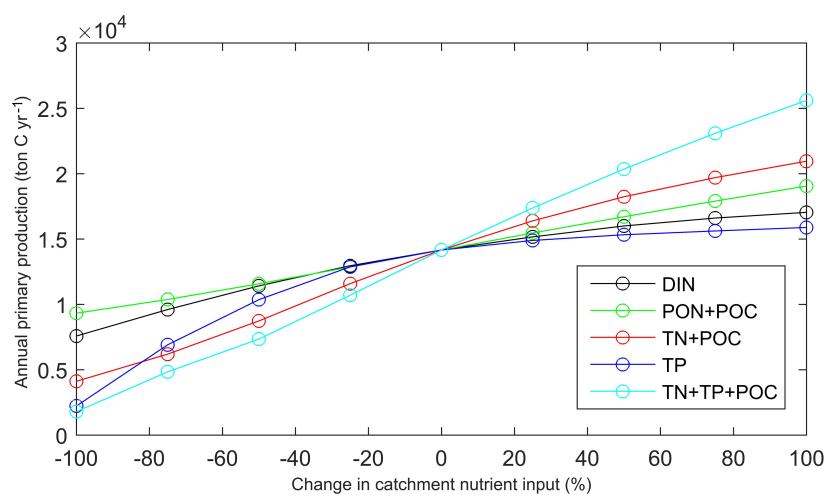

Figure 4. Modelled total primary production in Lake King between May 2010 and July 2012: DIN, change in dissolved inorganic nitrogen load; PON + POC, change in particulate organic nitrogen and carbon loads; $\mathrm{TN}+\mathrm{POC}$, change in total nitrogen and particulate organic carbon loads; TP, change in total phosphorus load; $\mathrm{TN}+\mathrm{TP}+\mathrm{POC}$, change in total nitrogen, total phosphorus and particulate organic carbon loads.

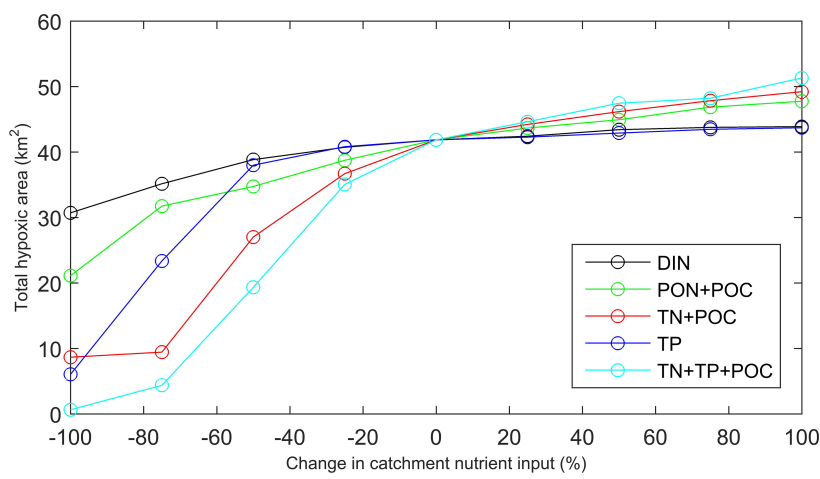

Figure 5. Modelled total area experiencing hypoxia in Lake King.

\subsection{Bottom-water oxygen}

The total area in Lake King covered by hypoxic bottom water was about $40 \mathrm{~km}^{2}$ for the base case (Fig. 5). Any further increase in catchment DIN or TP load had no obvious impact on the size of the total hypoxic area (the total area with $24 \mathrm{~h}$ averaged bottom-water DO concentration $<2 \mathrm{mg} \mathrm{L}^{-1}$ that occurred at least once), while slight increases were seen for the other three scenarios. This was because TPP did not increase much when either DIN or TP increased. Complete removal of catchment DIN and PON loads would result in 25 and $50 \%$ reductions in the total area covered by hypoxic bottom water. The decrease in hypoxic area was insignificant when the TP load was reduced by $50 \%$ but was followed by an accelerating decline if TP was further reduced. Conversely, the hypoxic area decreased more steadily when TN was reduced and the magnitude of decrease in the hypoxic area was most obvious when both $\mathrm{TN}$ and $\mathrm{TP}$ were reduced. The most severe and persistent hypoxia and/or anoxia was found in the northern Lake King basin. Therefore, the statis-

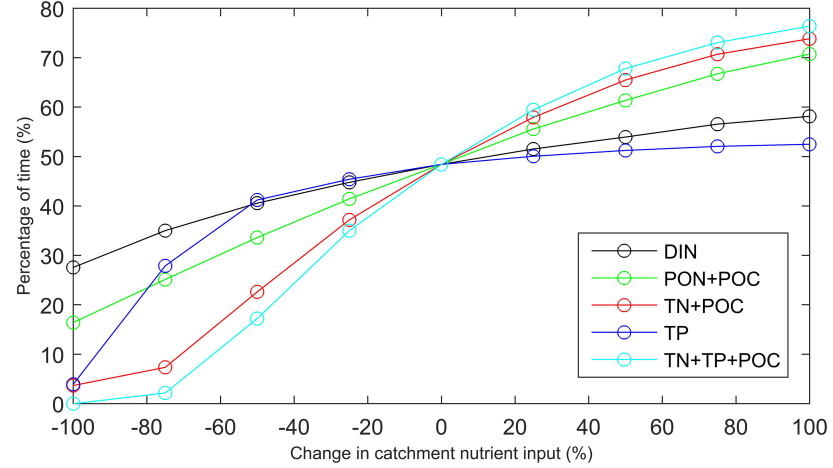

Figure 6. Occurrence of hypoxia as a percentage of time at LKN.

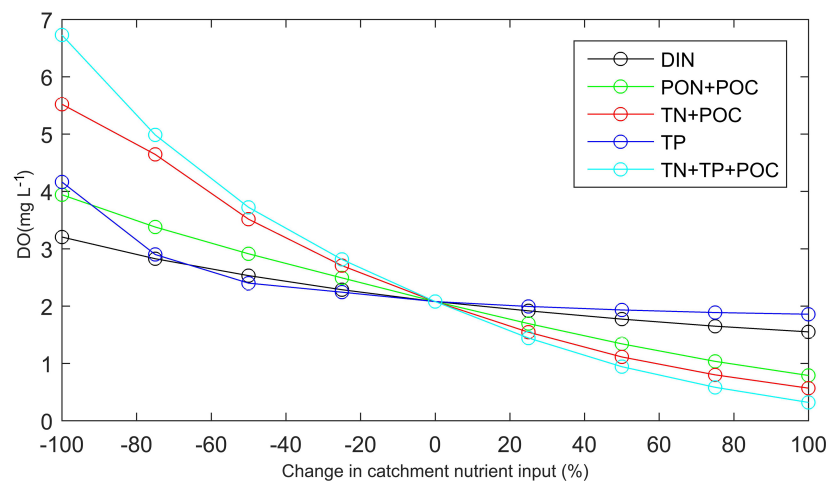

Figure 7. Median bottom-water DO concentration.

tics of the time series bottom DO concentration from Lake King North (LKN, location shown in Fig. 1) were extracted and analysed. It was found that the bottom-water DO concentration at $\mathrm{LKN}$ would still decrease to close to $0 \mathrm{mg} \mathrm{L}^{-1}$ even if either catchment TN or TP were completely removed. It would require complete removal of both catchment $\mathrm{TN}$ and TP input to eliminate hypoxia in the northern Lake King basin. For the base case, the bottom DO concentration was below the $2 \mathrm{mgL}^{-1}$ threshold for almost $43 \%$ of the time (Fig. 6) and the median bottom DO concentration was just slightly above $2 \mathrm{mgL}^{-1}$ (Fig. 7). Compared to DIN and TP, doubling the PON load would result in much more frequent hypoxia at LKN, and the occurrence of hypoxia could substantially increase by almost $70 \%$ and could also lead to a $73 \%$ reduction in median bottom DO concentration. This was likely because the POC was also adjusted with PON. The median DO concentration would significantly increase to $5.5 \mathrm{mg} \mathrm{L}^{-1}$ if catchment TN was completely removed. A $100 \%$ reduction in TP load would improve the median bottom DO concentrations to about $4 \mathrm{mg} \mathrm{L}^{-1}$ and reduction in PON would have a similar effect. Nonetheless, DIN tended to have a relatively smaller impact on the bottom DO concentrations at LKN. 


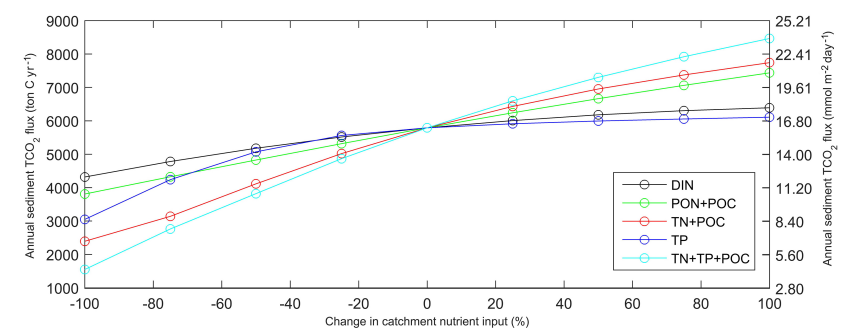

Figure 8. Annual sediment $\mathrm{TCO}_{2}$ flux from Lake King.

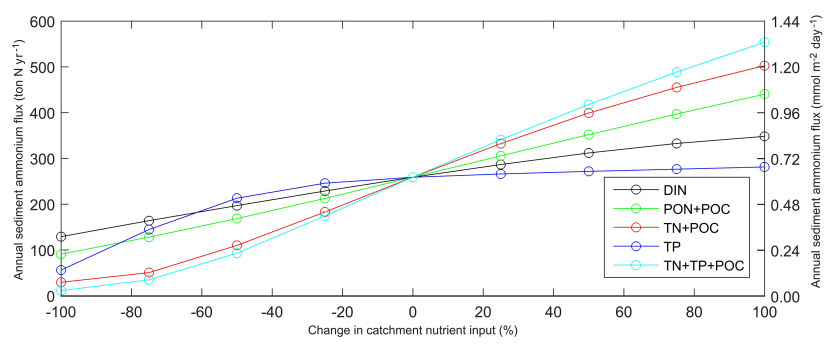

Figure 9. Annual sediment ammonia flux from Lake King.

\subsection{Sediment nutrient fluxes}

The total $\mathrm{CO}_{2}\left(\mathrm{TCO}_{2}\right)$ flux was a good indication of how much labile organic matter is deposited on the lake bed (Fig. 8). To compare the effect of nutrient reductions on $\mathrm{TCO}_{2}$ fluxes, the effect of the initial sediment nutrient condition was taken into account by subtracting the $\mathrm{TCO}_{2}$ flux and TPP for the simulation with no catchment nutrient input from all the model results. The $\mathrm{TCO}_{2}$ flux and TPP were highly correlated and the $\mathrm{TCO}_{2}$ flux was approximately equivalent to $8.5 \%$ (calculated by linear regression: $R^{2}=0.97$, $n=41)$ of the TPP across the entire lake system. The ratio was much higher at Lake King and increased to $33 \%$ $\left(R^{2}=0.93, n=41\right)$. This indicated that the deposition rate in Lake King was much higher than in the rest of the lakes and/or the deposited organic matter could have come from the other parts of the lakes. Increased PON loads resulted in a greater increase in $\mathrm{TCO}_{2}$ flux than DIN or TP. The sediment ammonia fluxes followed very similar trends to the $\mathrm{TCO}_{2}$ fluxes, whereas ammonia fluxes were more dependent on PON load (Fig. 9). The average annual nitrogen removal rate through denitrification was about $240 \mathrm{t} \mathrm{N}$ year $^{-1}$ in the sediment of Lake King for the base case. However, the nitrogen removal rate in Lake King for all the scenarios only varied marginally from the base case by around $\pm 15 \%$, except for the simulation of no anthropogenic nutrient load, which had a slightly higher reduction in denitrification rate at approximately $35 \%$. As a result, the denitrification efficiency in the sediment of Lake King had a negative correlation with the catchment nutrient load (Fig. 10).

Denitrification efficiency is a commonly used measure of the efficiency of nitrogen removal from sediments. It has

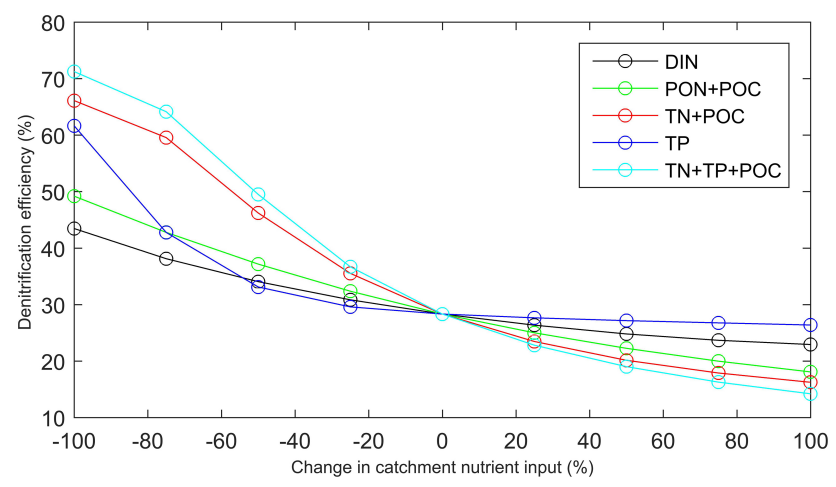

Figure 10. Annual average denitrification efficiency in Lake King.

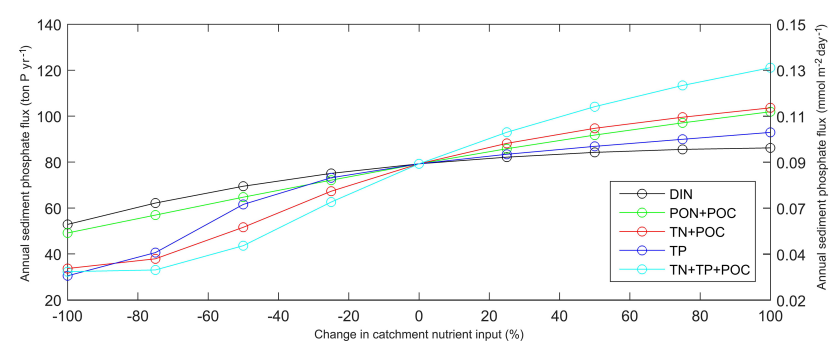

Figure 11. Annual sediment phosphate flux from Lake King.

been defined as the percentage of inorganic nitrogen released from the sediment as dinitrogen gas $\left(\mathrm{g} \mathrm{N} \mathrm{m}^{2} \mathrm{year}^{-1}\right)$ and can be calculated by $\left[\mathrm{N}_{2} /\left(\mathrm{FNH}+\mathrm{FN}_{3}+\mathrm{N}_{2}\right) \times 100 \%\right]$ (Eyre and Ferguson, 2009). FNH and $\mathrm{FN}_{3}$ are the sediment ammonia and nitrate fluxes in $\mathrm{gN} \mathrm{m}^{-2} \mathrm{year}^{-1}$. Interestingly, sediment phosphate flux was more sensitive to the change in $\mathrm{TN}$ rather than TP loads (Fig. 11). This was because the majority of the phosphate fluxes were a consequence of desorption processes under hypoxic and/or anoxic conditions. The results also showed that even if the catchment nutrient load was completely removed, it would not stop sediment phosphate release, and a $60 \%$ reduction was predicted. One explanation would be that the desorption process still took place as stratification prevented bottom-water oxygen replenishment after the flood event.

\section{Discussion}

Through observations and modelling, we have previously documented the seasonal dynamics of phytoplankton and nutrient cycling in the Gippsland Lakes (Cook and Holland, 2012; Cook et al., 2010). High winter inflows carried nitrogen into the Gippsland Lakes, which stimulated phytoplankton production. Inputs of organic matter from internal production and the catchment led to hypoxia throughout spring and summer, which then caused phosphorus release from the sediment. We now discuss the sensitivity of this conceptual model to changes in external nutrient loading rates. 


\subsection{Primary production}

Outside the summer cyanobacterial blooms, the lakes are typically nitrogen limited (Holland et al., 2012), and we therefore expected a strong sensitivity of primary production to nitrogen loading rates. Surprisingly, the model showed that primary production was equally sensitive to inorganic and particulate nitrogen loading and that there were two distinct mechanisms by which these two nitrogen forms were trapped within the lakes. Particulate nitrogen can settle down to the sediment while only a negligible portion of the inorganic nitrogen can be transported to the sediment by diffusion unless converted to particulate form by photosynthesis. To calculate how much PON or DIN could have been retained in the lakes after the floods in July and August 2011, we used the model to simulate the transport of PON and DIN, excluding all the biological and chemical processes. The results from this simulation showed that $79 \%$ of flood-introduced PON was retained in the lakes by the end of August. Of the retained labile PON, $95 \%$ reached the sediment where roughly $90 \%$ was recycled over the following 3 months. The importance of PON as a nitrogen source within aquatic systems depends strongly on the degradation kinetics. In this study, we estimated the degradation kinetics of PON based on a surprisingly small pool of literature (Cerco and Cole, 1994; Robson and Hamilton, 2004; DHI Water \& Environment, 2012; Deltares, 2013). We therefore suggest that further studies need to be undertaken to better understand the degradation kinetics of PON and the factors that control this such as land use, which may generate PON of different degradability.

Conversely, without any biogeochemical processes such as phytoplankton uptake, only $32 \%$ of the DIN remained in the lakes after the flood. In fact, all the simulations except for the TP reduction scenario showed that around $70 \%$ (calculated by linear regression: $R^{2}=0.99, n=37$ ) of TN contributed by the flood event still remained in the lakes by the end of August 2011. It is suggested that the majority of the DIN was assimilated by phytoplankton and settled to the sediment during the high flow period between July and August 2011. TN exported to the ocean as a percentage of the total catchment nitrogen input increased by 2.3, 8.1, 24 and $50 \%$ correspondingly when TP was reduced by $25,50,75$ and $100 \%$, implying that the $\mathrm{N}: \mathrm{P}$ ratio in flood waters can be an important factor controlling the residence time of flood-introduced TN in the lakes. This is also reflected in Fig. 9, which shows a sharp decline in sediment ammonia flux when catchment TP was reduced, highlighting the importance of biogeochemical factors in the residence time of nutrients in estuaries (Church, 1986). Under the same hydrodynamic conditions, nitrogen in particulate form has a longer residence time as it can settle down to the bottom of the lake but DIN can be assimilated by phytoplankton and converted to PON before being washed out of the lakes. The rate and efficiency of the conversion from DIN to PON ultimately determine the residence time of DIN in the system.

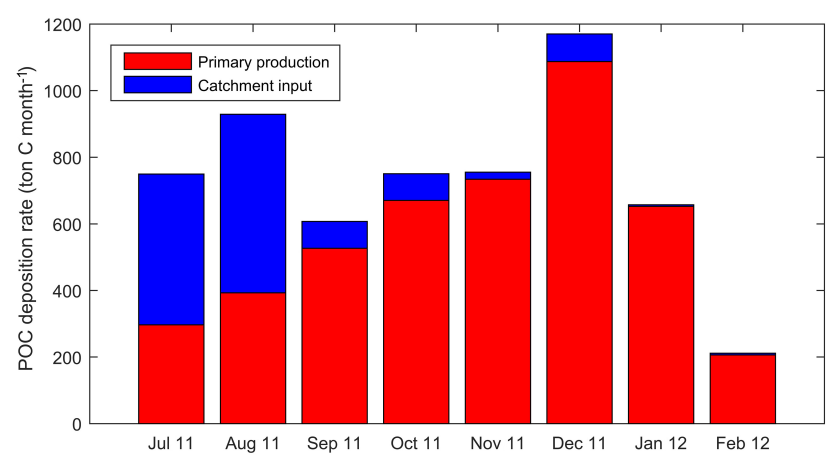

Figure 12. Sediment POC deposition rate at Lake King contributed by primary production and catchment input.

\subsection{Hypoxia}

Seasonal hypoxia is controlled by both stratification and inputs of organic carbon. The hypoxia observed in the Gippsland Lakes coincided with the recent transition to higher flow following the Millennium drought, which ended in 2010. Boesch et al. (2001) also reported the extended hypoxia in the Chesapeake Bay in the 1970s, which coincided with a transition from drought to wet years. Large freshwater inflows do not only enhance stratification but also increase catchment carbon and nutrient loads. Similar to many other estuary systems, such as the Baltic Sea (Conley et al., 2002) and the Black Sea (Capet et al., 2013), the suppressed oxygen replenishment due to stratification and high oxygen consumption from the mineralisation of deposited organic carbon were the main causes of the hypoxia in Lake King. Stratification in Lake King could last up to several months before the water column became well-mixed again. Lake King also had a higher deposition rate compared to the other parts of the lakes and the majority of the POC deposition was found to be in the deeper basin in northern Lake King. This was because a semi-closed circulation pattern was formed in this area as a result of the interaction between the outgoing river flow and the incoming tidal flow from the ocean, resulting in a lot of POC being trapped in the area unless there was a large flood or storm surge. Another important reason for POC retention in the Lake King basin was that the bottom shear stress in this area was generally low and the 90th percentile shear velocity was only $0.34 \mathrm{~cm} \mathrm{~s}^{-1}$, which was lower than the reported critical shear velocity $\left(0.4-0.8 \mathrm{~cm} \mathrm{~s}^{-1}\right)$ for the resuspension of phytoplankton-derived organic matter (Beaulieu, 2003). The normal current or wave conditions did not exert enough force to resuspend the sediment in this area once deposited. Furthermore, increases in nutrient load did not proportionally increase the total area subject to hypoxia in Lake King. This was because the areas subject to high detritus deposition were determined by the hydrodynamics and wave conditions, and these depositional areas remained the same for all nutrient scenarios. Furthermore, unlike the Baltic Sea 
where low DO water could move upwards from individual hypoxic basins and become connected to form a larger hypoxic region (Conley et al., 2009a), the Gippsland Lakes are a much shallower system and the bottom water in areas with depths $<3-4 \mathrm{~m}$ was frequently ventilated with wind-driven upwelling and incoming tidal currents, even during the stratified period, highlighting the importance of high organic matter loads in the Gippsland Lakes in maintaining hypoxia.

There has been controversy as to whether internal primary production stimulated directly by anthropogenic nutrients or external catchment organic carbon inputs caused hypoxia in estuaries such as the Gulf of Mexico (Boesch et al., 2009). Previous studies have suggested that carbon either derived from algal blooms or the catchment could result in estuarine hypoxia depending on the hydrological and meteorological conditions (Paerl et al., 1998). To compare the relative importance of the catchment carbon and primary production to the development of hypoxia in Lake King and sediment phosphorus flux, a mass balance calculation was undertaken to calculate the amount of labile POC deposited in the sediment of Lake King. The mass balance calculation was carried out for the period between July 2011 and January 2012 and this was when severe hypoxia and high sediment $P$ flux were observed (Fig. 12). As the model in the current study was not able to trace the origin of the POC, the mass balance calculation was only an approximation and was based on the difference between the base case and the simulation of complete removal of the catchment TN and TP. For a given period, the change in sediment labile POC $(\Delta \mathrm{C})$ is approximately equal to the sum of settled labile POC contributed by catchment input and primary production, subtracted from the sediment $\mathrm{CO}_{2}$ flux due to mineralisation of labile POC. If the conversion from labile to refractory $\mathrm{POC}$ can be excluded from the calculation, then sediment $\mathrm{TCO}_{2}$ flux for the zero catchment nutrient simulation can be assumed to be completely contributed by the mineralisation of refractory POC in the sediment (Cmr). The sediment $\mathrm{CO}_{2}$ flux due to mineralisation of labile $\mathrm{POC}$ is equal to sediment $\mathrm{TCO}_{2}$ flux minus $\mathrm{Cmr}$. Since the primary production for the zero catchment TP scenario between July 2011 and January 2012 was only equivalent to $0.38 \%$ of that for the base case, it can be assumed that all the sediment $\mathrm{POC}$ accumulation resulted from catchment input, which is given by $\Delta \mathrm{C}+\mathrm{TCO}_{2}-\mathrm{Cmr}$. By applying the same approach to the base case, the total POC deposited in the sediment from both catchment and internal generation can be calculated.

The 2011 winter flood brought approximately $4500 \mathrm{t}$ of labile organic carbon into the lakes and about $22 \%$ of this load settled in Lake King between July and August. For this period, catchment carbon contributed almost half of the sediment $\mathrm{TCO}_{2}$ flux in Lake King. However, bottom-water hypoxia did not develop in Lake King until mid-October, by which time most of the sediment labile POC derived from the catchment was mineralised based on the results of the zero-catchment TP simulation. The elevated temperature and higher light levels during November resulted in higher primary production, which consequently enhanced the sediment carbon enrichment and increased the mineralisation rate of sediment POC. Severe bottom-water hypoxia developed and lasted through towards the end of the simulation. In addition, the catchment POC only contributed less than $7 \%$ to the sediment $\mathrm{TCO}_{2}$ flux between September 2011 and January 2012. This number is very close to the catchment POC to TPP ratio of $8.3 \%$ for the entire 2-year simulation period. Therefore, bottom-water oxygen depletion in Lake King was primarily related to the planktonic organic matter stimulated by nutrient fluxes from the catchment.

\subsection{Internal nutrient dynamics}

Internal nutrient recycling can be a critical supply of nutrients to algal growth and it is therefore important to consider the sensitivity of these processes to changes in external loading. Consistent with previous studies (Mulholland et al., 2008; Gardner and McCarthy, 2009), denitrification efficiency increased with reduced nitrogen loading rates, which reduced sediment hypoxia and sediment organic carbon mineralisation rates. Interestingly, at high reductions in phosphorus loading, there was also a large increase in denitrification efficiency, which resulted from the already noted transition to $\mathrm{P}$ limitation, meaning less organic nitrogen input to the sediment.

We have previously shown that the primary source of phosphorus fuelling summer blooms of $\mathrm{N}$-fixing cyanobacteria was from the sediment (Scicluna et al., 2015; Zhu et al., 2016). This sediment release of phosphorus was induced by hypoxia, which was in turn driven by internal primary production. As already discussed, this primary production was driven by nitrogen during the winter and spring months and one would therefore expect sediment phosphorus release to be sensitive to nitrogen loads. Importantly, the model showed that internal phosphorus release from the sediment was more sensitive to TN loading than it was to total phosphorus loading at load reductions $<80 \%$. Conversely, increases in total phosphorus loads were expected to have a minimal effect on internal phosphorus recycling. There has previously been strong debate as to the importance of nitrogen versus phosphorus in coastal systems and it has been argued that the key focus of eutrophication management is to control phosphorus as it is the nutrient that ultimately limits productivity (Schindler et al., 2008). Using a mechanistic approach, the present study highlights that both $\mathrm{N}$ and $\mathrm{P}$ reductions are required to reduce internal recycling of phosphorus and that phosphorus load reductions alone are likely to be ineffective (Paerl, 2009; Conley et al., 2009b). 


\subsection{Management implications}

Compared to DIN, PON had a slightly larger impact on the bottom DO concentration in Lake King most likely because POC load was related to PON load. The results showed that LKN was more susceptible to TN loading to a certain extent when compared to TP. However, initial input of catchment phosphorus was essential to stimulate primary production, which contributed the majority of the carbon enrichment in the sediment. To eliminate hypoxia in the Gippsland Lakes within the timescale ( $\sim 2$ years) of the current model simulation would require a complete removal of catchment nutrient input. Many studies have demonstrated that the effectiveness of external nutrient reduction could be compromised by the sediment supply (Rossi and Premazzi, 1991; Istvánovics et al., 2002; Søndergaard et al., 2003; Jeppesen et al., 2005; Wu et al., 2017). In reality, it is very difficult to reduce nutrients sufficiently and for long enough. It has previously been estimated that the feasible reductions in TN and TP were only $25 \%$ (Ladson, 2012) and $20 \%$ (Roberts et al., 2012), respectively, for the Gippsland Lakes. The results showed that even if the feasible reduction target was achieved, the immediate improvement in the water quality in the lakes was marginal.

For the Gippsland Lakes, the majority of the catchment nutrient flux was non-point source introduced by the flood, making it difficult to manage. The reduction in dissolved inorganic nutrients in flood waters would be particularly more challenging. However, the current study has shown that the water quality in the lakes was also largely influenced by particulate nitrogen and phosphorus, each of which comprised about 60 and $80 \%$ of the total catchment loads, respectively, between 2005 and 2011. Therefore, erosion control is the key to reduce particulate nutrient load from a non-point source and to improve the water quality in the Gippsland Lakes. Vegetated buffers, particularly riparian forests, have been considered to be the simplest but the most effective management option to reduce agricultural non-point source pollutants (Phillips, 1989), especially for nutrient in particulate forms. Vegetated buffers have formed an important part of the water quality improvement strategies for many coastal and estuarine systems such as the Gulf of Mexico (Mitsch et al., 2001) and Chesapeake Bay (Lowrance et al., 1997). Zhang et al. (2010) analysed more than 50 published studies on the performance of vegetated buffers on nutrient removal and found that the median removal efficiency was $68 \%$ for nitrogen and $72 \%$ for phosphorus. However, the performance of vegetated buffers can be compromised on a catchment scale and the removal efficiency can be reduced dramatically to less than $20 \%$ (Verstraeten et al., 2006), due to subsurface hydrological pathways, breakthrough surface runoff or bypass through roads (Mainstone and Parr, 2002). Other measures such as modification in agricultural practices should also be considered. Carefully designed and properly managed vegetated buffers can be a part of an integrated non- point source control strategy for estuarine water quality improvement.

\section{Conclusion}

Hypoxia and associated sediment phosphorus release in Lake King were predominantly driven by stratification and sediment carbon enrichment. Primary production stimulated by nitrogen loads rather than catchment organic carbon input contributed the majority of the carbon enrichment and was therefore responsible for the depletion of bottom-water DO in summer. Although a significant amount of phosphorus was stored in the sediment, it would only be released under low bottom-water DO conditions in which a large quantity of POC settled in the sediment, which was ultimately driven by nitrogen loading. In addition, the residence time of floodintroduced DIN could be largely influenced by a number of factors including the availability of phosphorus in flood water. It was found that DIN introduced by floods could be converted to PON by photosynthesis quickly enough to prevent being flushed out of the lakes. The current study demonstrated that it is important to reduce both TN and TP in hypoxia mitigation in estuarine systems.

Data availability. The model data are available upon request to the corresponding author (Yafei Zhu, yafei.zhu@monash.edu).

Competing interests. The authors declare that they have no conflict of interest.

Acknowledgements. This work was supported by the Australian research council grant LP140100087 to PLMC and the Victorian Department of Environment, Land, Water and Planning. The authors also thank DHI for provision of licenses for MIKE21 SW, MIKE3 FM and ECO Lab.

Edited by: Caroline P. Slomp

Reviewed by: two anonymous referees

\section{References}

Beaulieu, S. E.: Resuspension of phytodetritus from the sea floor: A laboratory flume study, Limnol. Oceanogr., 48, 1235-1244, 2003.

Boesch, D. F., Brinsfield, R. B., and Magnien, R. E.: Chesapeake bay eutrophication, J. Environ. Qual., 30, 303-320, 2001.

Boesch, D. F., Boynton, W. R., Crowder, L. B., Diaz, R. J., Howarth, R. W., Mee, L. D., Nixon, S. W., Rabalais, N. N., Rosenberg, R., and Sanders, J. G.: Nutrient enrichment drives Gulf of Mexico hypoxia, Eos, Transactions American Geophysical Union, 90, 117-118, 2009. 
Capet, A., Beckers, J.-M., and Grégoire, M.: Drivers, mechanisms and long-term variability of seasonal hypoxia on the Black Sea northwestern shelf - is there any recovery after eutrophication?, Biogeosciences, 10, 3943-3962, https://doi.org/10.5194/bg-103943-2013, 2013.

Capet, A., Stanev, E. V., Beckers, J.-M., Murray, J. W., and Grégoire, M.: Decline of the Black Sea oxygen inventory, Biogeosciences, 13, 1287-1297, https://doi.org/10.5194/bg-13-12872016, 2016.

Cerco, C. F. and Cole, T. M.: Three-Dimensional Eutrophication Model of Chesapeake Bay, Volume 1: Main Report, DTIC Document, 1994.

Church, T. M.: Biogeochemical factors influencing the residence time of microconstituents in a large tidal estuary, Delaware Bay, Mar. Chem., 18, 393-406, 1986.

Conley, D. J., Humborg, C., Rahm, L., Savchuk, O. P., and Wulff, F.: Hypoxia in the Baltic Sea and basin-scale changes in phosphorus biogeochemistry, Environ. Sci. Technol., 36, 5315-5320, 2002.

Conley, D. J., Björck, S., Bonsdorff, E., Carstensen, J., Destouni, G., Gustafsson, B. G., Hietanen, S., Kortekaas, M., Kuosa, H., and Markus Meier, H.: Hypoxia-related processes in the Baltic Sea, Environ. Sci. Technol., 43, 3412-3420, 2009a.

Conley, D. J., Paerl, H. W., Howarth, R. W., Boesch, D. F., Seitzinger, S. P., Havens, K. E., Lancelot, C., and Likens, G. E.: Controlling eutrophication: nitrogen and phosphorus, Science, 323, 1014-1015, 2009b.

Cook, P. L. M. and Holland, D. P.: Long term nutrient loads and phytoplankton dynamics in a large temperate Australian lagoon system affected by recurring blooms of Nodularia spumigena, Biogeochemistry, 107, 261-274, 2012.

Cook, P. L. M., Holland, D. P., and Longmore, A. R.: Effect of a flood event on the dynamics of phytoplankton and biogeochemistry in a large temperate Australian lagoon, Limnol. Oceanogr., 55, 1123-1133, 2010.

Correll, D. L.: The role of phosphorus in the eutrophication of receiving waters: A review, J. Environ. Qual., 27, 261-266, 1998.

Deltares: D-Water Quality Processes Technical Reference Manual, Delft Hydraulics, the Netherlands, 2013.

DHI Water \& Environment: DHI Eutrophication Model 1, ECO Lab Template, DHI Water \& Environment, Denmark, 2012.

Diaz, R. J.: Overview of hypoxia around the world, J. Environ. Qual., 30, 275-281, 2001.

Diaz, R. J. and Rosenberg, R.: Spreading dead zones and consequences for marine ecosystems, Science, 321, 926-929, 2008.

Eyre, B. D. and Ferguson, A. J.: Denitrification efficiency for defining critical loads of carbon in shallow coastal ecosystems, Hydrobiologia, 629, 137-146, 2009.

Gardner, W. S. and McCarthy, M. J.: Nitrogen dynamics at the sediment-water interface in shallow, sub-tropical Florida Bay: why denitrification efficiency may decrease with increased eutrophication, Biogeochemistry, 95, 185-198, 2009.

Hagy, J. D., Boynton, W. R., Keefe, C. W., and Wood, K. V.: Hypoxia in Chesapeake Bay, 1950-2001: long-term change in relation to nutrient loading and river flow, Estuaries, 27, 634-658, 2004.

Holland, D. P., Van Erp, I. C., Beardall, J., and Cook, P. L. M.: Environmental controls on the growth of the nitrogen-fixing cyanobacterium Nodularia spumigena Mertens in a temperate la- goon system in South-Eastern Australia, Mar. Ecol.-Prog. Ser., 461, 47-57, 2012.

Holland, D., Jennings, M., Beardall, J., Gell, P., Doan, P., Mills, K., Briles, C., Zawadzki, A., and Cook, P.: Two hundred years of blue-green algae blooms in the Gippsland Lakes, Water Studies Centre, Moans University, Melbourne, Australia, 2013.

Howarth, R. W. and Marino, R.: Nitrogen as the limiting nutrient for eutrophication in coastal marine ecosystems: evolving views over three decades, Limnol. Oceanogr., 51, 364-376, 2006.

Howarth, R., Chan, F., Conley, D. J., Garnier, J., Doney, S. C., Marino, R., and Billen, G.: Coupled biogeochemical cycles: eutrophication and hypoxia in temperate estuaries and coastal marine ecosystems, Front. Ecol. Environ., 9, 18-26, 2011.

Istvánovics, V., Somlyódy, L., and Clement, A.: Cyanobacteriamediated internal eutrophication in shallow Lake Balaton after load reduction, Water Res., 36, 3314-3322, 2002.

Jeppesen, E., Søndergaard, M., Jensen, J. P., Havens, K. E., Anneville, O., Carvalho, L., Coveney, M. F., Deneke, R., Dokulil, M. T., and Foy, B.: Lake responses to reduced nutrient loadingan analysis of contemporary long-term data from 35 case studies, Freshwater Biol., 50, 1747-1771, 2005.

Kiirikki, M., Inkala, A., Kuosa, H., Pitkänen, H., Kuusisto, M., and Sarkkula, J.: Evaluating the effects of nutrient load reductions on the biomass of toxic nitrogen-fixing cyanobacteria in the Gulf of Finland, Baltic Sea, Boreal Environ. Res., 6, 131-146, 2001.

Ladson, A.: Importance of catchment-sourced nitrogen loads as a factor in determining the health of the Gippsland Lakes, Gippsland Lakes and Catchments Task Force, Melbourne, Australia, 2012.

Longmore, A. R.: Gippsland Lakes sediment nutrient inventory, Marine and Freshwater Resources Institute, Queenscliff, Australia, 2000.

Lowrance, R., Altier, L. S., Newbold, J. D., Schnabel, R. R., Groffman, P. M., Denver, J. M., Correll, D. L., Gilliam, J. W., Robinson, J. L., and Brinsfield, R. B.: Water quality functions of riparian forest buffers in Chesapeake Bay watersheds, Environ. Manage., 21, 687-712, 1997.

Mainstone, C. P. and Parr, W.: Phosphorus in rivers - ecology and management, Sci. Total Environ., 282, 25-47, 2002.

Mayer, L. M., Keil, R. G., Macko, S. A., Joye, S. B., Ruttenberg, K. C., and Aller, R. C.: Importance of suspended particulates in riverine delivery of bioavailable nitrogen to coastal zones, Global Biogeochem. Cy., 12, 573-579, 1998.

Meybeck, M.: Carbon, nitrogen, and phosphorus transport by world rivers, Am. J. Sci., 282, 401-450, 1982.

Mitsch, W. J., Day Jr., J. W., Gilliam, J. W., Groffman, P. M., Hey, D. L., Randall, G. W., and Wang, N.: Reducing Nitrogen Loading to the Gulf of Mexico from the Mississippi River Basin: Strategies to Counter a Persistent Ecological Problem: Ecotechnology - the use of natural ecosystems to solve environmental problems - should be a part of efforts to shrink the zone of hypoxia in the Gulf of Mexico, BioScience, 51, 373-388, 2001.

Mulholland, P. J., Helton, A. M., Poole, G. C., Hall, R. O., Hamilton, S. K., Peterson, B. J., Tank, J. L., Ashkenas, L. R., Cooper, L. W., and Dahm, C. N.: Stream denitrification across biomes and its response to anthropogenic nitrate loading, Nature, 452, 202-205, 2008.

Neumann, T., Fennel, W., and Kremp, C.: Experimental simulations with an ecosystem model of the Baltic Sea: A nutrient load re- 
duction experiment, Global Biogeochem. Cycles, 16, 7-1-7-19, https://doi.org/10.1029/2001GB001450, 2002.

Paerl, H.: Controlling Eutrophication along the Freshwater-Marine Continuum: Dual Nutrient (N and P) Reductions are Essential, Estuar. Coast., 32, 593-601, 2009.

Paerl, H. W., Mallin, M. A., Donahue, C. A., Go, M., and Peierls, B. L.: Nitrogen loading sources and eutrophication of the Neuse River Estuary, North Carolina: Direct and indirect roles of atmospheric deposition, Water Resources Research Institute of the University of North Carolina, 1995.

Paerl, H. W., Pinckney, J. L., Fear, J. M., and Peierls, B. L.: Ecosystem responses to internal and watershed organic matter loading: consequences for hypoxia in the eutrophying Neuse River Estuary, North Carolina, USA, Mar. Ecol.-Prog. Ser., 166, 17-25, 1998.

Phillips, J. D.: Nonpoint source pollution control effectiveness of riparian forests along a coastal plain river, J. Hydrol., 110, 221237, 1989.

Pitkänen, H., Kiirikki, M., Savchuk, O. P., Räike, A., Korpinen, P., and Wulff, F.: Searching efficient protection strategies for the eutrophied Gulf of Finland: the combined use of 1D and 3D modeling in assessing long-term state scenarios with high spatial resolution, AMBIO, 36, 272-279, 2007.

Rabalais, N. N., Turner, R., Gupta, B. S., Boesch, D., Chapman, P., and Murrell, M.: Hypoxia in the northern Gulf of Mexico: Does the science support the plan to reduce, mitigate, and control hypoxia?, Estuar. Coast., 30, 753-772, 2007.

Roberts, A. M., Pannell, D. J., Doole, G., and Vigiak, O.: Agricultural land management strategies to reduce phosphorus loads in the Gippsland Lakes, Australia, Agr. Syst., 106, 11-22, 2012.

Robson, B. J. and Hamilton, D. P.: Three-dimensional modelling of a Microcystis bloom event in the Swan River estuary, Western Australia, Ecolog. Model., 174, 203-222, 2004.

Rossi, G. and Premazzi, G.: Delay in lake recovery caused by internal loading, Water Res., 25, 567-575, 1991.

Schindler, D. W., Hecky, R., Findlay, D., Stainton, M., Parker, B., Paterson, M., Beaty, K., Lyng, M., and Kasian, S.: Eutrophication of lakes cannot be controlled by reducing nitrogen input: results of a 37-year whole-ecosystem experiment, P. Natl. Acad. Sci. USA, 105, 11254-11258, 2008.

Scicluna, T. R., Woodland, R. J., Zhu, Y. F., Grace, M. R., and Cook, P. L. M.: Deep dynamic pools of phosphorus in the sediment of a temperate lagoon with recurring blooms of diazotrophic cyanobacteria, Limnol. Oceanogr., 60, 2185-2196, 2015.
Seitzinger, S., Kroeze, C., Bouwman, A., Caraco, N., Dentener, F., and Styles, R.: Global patterns of dissolved inorganic and particulate nitrogen inputs to coastal systems: Recent conditions and future projections, Estuaries, 25, 640-655, 2002.

Skerratt, J., Wild-Allen, K., Rizwi, F., Whitehead, J., and Coughanowr, C.: Use of a high resolution 3D fully coupled hydrodynamic, sediment and biogeochemical model to understand estuarine nutrient dynamics under various water quality scenarios, Ocean Coast. Manage., 83, 52-66, 2013.

Søndergaard, M., Jensen, J. P., and Jeppesen, E.: Role of sediment and internal loading of phosphorus in shallow lakes, Hydrobiologia, 506, 135-145, 2003.

Turner, R., Rabalais, N., Alexander, R., McIsaac, G., and Howarth, R.: Characterization of nutrient, organic carbon, and sediment loads and concentrations from the Mississippi River into the Northern Gulf of Mexico, Estuar. Coast., 30, 773-790, 2007.

Vahtera, E., Conley, D. J., Gustafsson, B. G., Kuosa, H., Pitkänen, H., Savchuk, O. P., Tamminen, T., Viitasalo, M., Voss, M., and Wasmund, N.: Internal ecosystem feedbacks enhance nitrogenfixing cyanobacteria blooms and complicate management in the Baltic Sea, AMBIO, 36, 186-194, 2007.

Verstraeten, G., Poesen, J., Gillijns, K., and Govers, G.: The use of riparian vegetated filter strips to reduce river sediment loads: an overestimated control measure?, Hydrol. Process., 20, 42594267, 2006.

Webster, I. T., Parslow, J. S., Grayson, R. B., Molloy, R. P., Andrewartha, J., Sakov, P., Tan, K. S., Walker, S. J., and Wallace, B. B.: Assessing Options for Improving Water Quality and Ecological Function, Gippsland Lakes Environmental Study, Gippsland Coastal Board, Melbourne, Australia, 2001.

Wu, Z., Liu, Y., Liang, Z., Wu, S., and Guo, H.: Internal cycling, not external loading, decides the nutrient limitation in eutrophic lake: A dynamic model with temporal Bayesian hierarchical inference, Water Res., 116, 231-240, 2017.

Zhang, X., Liu, X., Zhang, M., Dahlgren, R. A., and Eitzel, M.: A review of vegetated buffers and a meta-analysis of their mitigation efficacy in reducing nonpoint source pollution, J. Environ. Qual., 39, 76-84, 2010.

Zhu, Y., Hipsey, M. R., McCowan, A., Beardall, J., and Cook, P. L. M.: The role of bioirrigation in sediment phosphorus dynamics and blooms of toxic cyanobacteria in a temperate lagoon, Environ. Modell. Softw., 86, 277-304, 2016. 